\title{
Farklı posterior kompozit rezinlerde su emilimi, çözünürlük ve mikrosertlik değişimlerinin incelenmesi
}

\author{
Çiğdem Atalayın(0000-0003-4144-4233) ${ }^{\alpha}$, Gamze Karaçolak(0000-0002-7090-1360) ${ }^{\alpha}$, Ayşegül Kaya(0000-0002-7271-047X) ${ }^{\alpha}$ \\ Selcuk Dent J, 2018; 5: 117-122 (Doi: 10.15311/selcukdentj. 329999) \\ Başvuru Tarihi: 20 Temmuz 2017 \\ Yayına Kabul Tarihi: 01 Kasım 2017
}

Öz

Farklı posterior kompozit rezinlerde su emilimi, çözünürlük ve mikrosertlik değişimlerinin incelenmesi

Amaç: : $\mathrm{Bu}$ in vitro çalışmanın amacı farklı posterior kompozitlerin su emilimi, çözünürlük ve mikrosertlik değerlerinin zaman içindeki değişimlerini incelemektir.

Gereç ve Yöntemler: : Çalışmada beş farkı kompozit (Ceram-X One Universal-Dentsply, G-aenial posterior-GC, Charisma SmartHeraus-Kulzer, X-tra fil-Voco ve Filtek Z550-3M-ESPE) ve bir cam iyonomer siman (Ketac Molar Easymix-3M-ESPE) kullanıldı. Materyallerin su emilimi ve suda çözünürlükleri ISO 4049 standartlarına göre incelendi. Materyallerin üç farklı zaman aralığında (başlangıç, 28 gün suda bekletme sonrası ve 90 gün desikatörde bekletme sonrası) mikrosertlik ölçümleri yapıldı. Verilerin istatistiksel analizi \% 95 güven aralığında tek yönlü varyans analizi (ANOVA) ve Bonferroni testi ile gerçekleştirildi.

Bulgular: Tüm kompozit materyaller ISO 4049 kriterlerine uygun olarak $40 \mu \mathrm{g} / \mathrm{mm}^{3}$ 'den daha az su emilimi gösterdi. Bu kriterlere uymayan ve en yüksek su emilimi değeri Ketac Molar Easymix'de $\left(78.44 \pm 5.14 \mu \mathrm{g} / \mathrm{mm}^{3}\right)$ saptandı $(\mathrm{p}<0.05)$. Materyallerin tümü ISO 4049 kriterlerine uygun olarak $7.5 \mu \mathrm{g} / \mathrm{mm}^{3}$ 'den daha az çözünürlük gösterdi. Su emilimi, çözünürlük ve üç farklı zaman aralığındaki mikrosertlik değerleri arasındaki korelasyon incelendiğinde, materyallere göre farklılık olduğu belirlendi.

Sonuç: Çözünürlük, su emilimi ve mikrosertlik gibi temel mekanik özellikler klinisyenlerin materyal seçiminde etkili olsa da, materyallerin diğer fiziksel, kimyasal ve biyolojik özelliklerinin de dikkate alınması gerektiği unutulmamalıdır.

\section{ANAHTAR KELIMELER}

Bileşik rezinler, çözünürlük, mikrosertlik, su emilimi

Günümüz diş hekimliği pratiğinde posterior bölgede kompozit ve cam iyonomer restorasyonlar oldukça yaygın bir kullanım alanına sahiptir. Ancak söz konusu bu restorasyonların amalgam restorasyonlarla karşıllaştırıldığında değiştirme riskinin yüksek olması, ${ }^{1}$ kullanım sürelerinin sorgulanmasına yol açmaktadır. Bu sebeple piyasada son dönemde posterior bölgede kullanılmak üzere mekanik özellikleri geliştirilen geniş bir ürün yelpazesi bulunmaktadır. Klinisyenler bu geniş ürün yelpazesi içinden kullanacakları ürünü seçerken çeşitli kriterleri esas almaktadır. Restoratif materyal

\section{ABSTRACT}

Water sorption, solubility and microhardness changes of different posterior composites

Background: The aim of this in vitro study was to evaluate the water sorption, solubility and microhardness changes of posterior composites over time.

Methods: Five composites (Ceram-X One Universal-Dentsply, G-aenial posterior-GC, Charisma Smart-Heraus-Kulzer, X-tra filVoco and Filtek Z550-3M-ESPE) and a glass-ionomer cement (Ketac Molar Easymix-3M-ESPE) were used. The water sorption and solubility were assessed according to ISO 4049 standards. Microhardness measurements were made at three different time-intervals (initial, after water storage for 28 days and after desiccator storage for 90 days). Statistical analysis of the data was performed by one way variance analysis (ANOVA) and Bonferroni test at 95\% confidence interval.

Results: The water sorption of all composites were less than $40 \mu \mathrm{g} / \mathrm{mm}^{3}$ in accordance with ISO 4049. The highest water sorption $\left(78.44 \pm 5.14 \mu \mathrm{g} / \mathrm{mm}^{3}\right)$ was found in Ketac Molar Easymix $(p<0.05)$. All of the materials showed less than 7.5 $\mu \mathrm{g} / \mathrm{mm}^{3}$ solubility in accordance with ISO 4049 . The correlation between water sorption, solubility and microhardness was determined to vary according to the materials.

Conclusion: Although the mechanical properties such as water sorption, solubility and microhardness are effective in material selection, other physical, chemical and biological properties should be also considered.

\section{KEYWORDS}

Composite resins, solubility, microhardness, water sorption

seçimini etkileyen en önemli faktörlerden biri materyalin mekanik özellikleridir. Çözünürlük, su emilimi ve mikrosertlik gibi mekanik özellikler materyallerin uzun dönem klinik performansı hakkında klinisyenlere fikir vermektedir.

Ağız içi dinamik koşullarda sürekli oral sıvılarla temas halinde kalacak olan materyaller için su emilimi ve çözünürlük klinik başarı açısından önem teşkil etmektedir. Materyal yapısında hidrolitik bozulmalara neden olan su emilimi,

\footnotetext{
${ }^{\alpha}$ Ege Üniversitesi Diş Hekimliği Fakültesi Restoratif Diş Tedavisi Anabilim Dalı, İzmir, Türkiye
} 
fiziksel ve kimyasal yapıyı da değiştirerek materyalin mekanik özelliklerini olumsuz etkilemektedir. İlaveten su emilimi kompozit rezinlerin hidrolitik stabilitesini bozarak renklenmeye neden olmaktadır. Su emiliminin aşınma direncinde azalmaya, hidrolitik degradasyona ve higroskopik ekspansiyona neden olduğu bildirilmiştir. ${ }^{2-6}$ Ayrıca su emilimi nedeniyle oluşan higroskopik stresin restore edilen dişte çatlaklara veya tüberkül kırıklarına neden olabileceği de bilinmektedir. ${ }^{7}$ Materyalin suda çözünürlüğünün ise kimyasal çözünürlüğü artırabileceği ve biyolojik uyumluluğu da etkileyebileceği düşünülebilir.

Söz konusu sorunlara çözüm getirmek üzere yeni formülasyonlara sahip materyaller geliştirilmiştir. $\mathrm{Bu}$ materyallerin geliştirilmesindeki amaç, klinik kullanım sürelerini uzatarak klinik başarıyı artırmaktır. Bu materyallerde doldurucu ve matris içeriğindeki modifikasyonlarla fiziksel ve mekanik özelliklerinin geliștirilmesi hedeflenmektedir. Örneğin geleneksel hibrit kompozitlerin yarısı kadar partikül büyüklüğüne sahip mikrohibrit kompozitler ön ve arka bölgede kullanım, kolay uygulanabilirlik, daha iyi parlatma gibi özellikleri geliştirilmek üzere üretilmiştir. ${ }^{8}$ Posterior bölgedeki intiyaçlar doğrultusunda geliştirilen, pre-polimerize doldurucu içeren mikrohibrit kompozitler de mevcuttur. Posterior bölgedeki intiyaçlar doğrultusunda geliştirilen alternatif formülasyona sahip bir diğer materyal, organik modifiye seramik ve eter-metakrilat kombinasyonunu içeren modifiye kompozittir. Bu materyalin içeriğindeki organik ve inorganik gruplar bağlanarak hibrit bir ağ oluşturmaktadır. ${ }^{3}$ Nanoteknoloji alanındaki ilerlemeler doğrultusunda geliştirilen nano-partikül boyutunda doldurucuya sahip nanokompozitlerde ise estetik ve mekanik özelliklerinin artırıması hedeflenmektedir. ${ }^{9}$ Nano-kompozitlerin üstün sertlik, esneklik, elastisite, estetik görünüm, kolay uygulama ve iyi parlatılabilme özellikleri en önemli avantajlarıdır. ${ }^{10}$

$\mathrm{Bu}$ in vitro çalışmanın amacı posterior bölgede kullanım için üretilmiş farklı kompozitlerin su emilimi, çözünürlük ve mikrosertlik değerlerinin zaman içinde değişimlerini incelemektir.

\section{GEREÇ VE YÖNTEM}

Çalışmada beş farklı kompozit ve bir cam iyonomer siman olmak üzere altı farklı restorasyon materyali kullanıldı. Bu materyallere ait bilgiler Tablo 1'de özetlenmiştir. Her bir materyalden plastik kalıplar kullanılarak $8 \mathrm{~mm}$ çap ve $2 \mathrm{~mm}$ yüksekliğe sahip disk-şeklinde örnekler hazırlandı $(n=10)$. Örnekler düz bir yüzey
Tablo 1.

\section{Çalışmada kullanılan restorasyon materyallerine ait bilgiler (İçerik bilgileri üretici firmaların beyanı doğrultusundadır)}

\begin{tabular}{|c|c|c|c|c|c|}
\hline Marka & Materyal & İçeriği & $\begin{array}{l}\text { Doldurucu } \\
\text { Oranı }\end{array}$ & Üretici & $\begin{array}{l}\text { Lot } \\
\text { Numarası }\end{array}$ \\
\hline $\begin{array}{l}\text { Ceram-X } \\
\text { One } \\
\text { Universal }\end{array}$ & $\begin{array}{l}\text { Nano- } \\
\text { seramik } \\
\text { universal } \\
\text { kompozit }\end{array}$ & $\begin{array}{l}\text { Metakrilat modifiye } \\
\text { polisiloksan (organik } \\
\text { modifiye seramik), } \\
\text { dimetakrilat rezinler, } \\
\text { floresan pigment, UV } \\
\text { stabilizör, } \\
\text { kamforokinon, Etil-4 } \\
\text { (dimetilamin) benzoat, } \\
\text { baryum-aliminyum- } \\
\text { borosilikat cam, silikon } \\
\text { dioksit nano } \\
\text { doldurucu, pigmentler }\end{array}$ & $\begin{array}{l}\text { Hacimce } \\
\% 55 \\
\text { Ağırlıkça } \\
\% 77\end{array}$ & Dentsply & 1503000268 \\
\hline $\begin{array}{l}\text { G-aenial } \\
\text { posterior }\end{array}$ & $\begin{array}{l}\text { Mikrohibrit } \\
\text { posterior } \\
\text { kompozit }\end{array}$ & $\begin{array}{l}\text { Metakrilat monomerleri } \\
\text { (UDMA ve dimetakrilat } \\
\text { ko-monomerleri) } \\
\text { Pre-polimerize } \\
\text { doldurucular }(16-17 \mu) \text { : } \\
\text { Silika içerikli, } \\
\text { Stronsiyum ve } \\
\text { Lanthanoid, Flor içerikli } \\
\text { İnorganik doldurucular } \\
>100 \text { nm: } \\
\text { Floroaluminosilikat } \\
\text { İnorganik doldurucular } \\
<100 \text { nm: silika } \\
\text { İz miktarda pigmentler, } \\
\text { katalistler } \\
\text { (Bis-GMA içermez.) }\end{array}$ & $\begin{array}{l}\text { Ağırlıkça } \\
\% 81\end{array}$ & $\mathrm{GC}$ & 1409222 \\
\hline $\begin{array}{l}\text { Charisma } \\
\text { Smart }\end{array}$ & $\begin{array}{l}\text { Mikrohibrit } \\
\text { kompozit }\end{array}$ & $\begin{array}{l}\text { BIS-GMA matris, } 0.005 \\
-10 \mu \text { m partikül } \\
\text { boyutuna sahip } \\
\text { doldurucu: Baryum } \\
\text { Aliminyum Flor cam, } \\
\text { dağıtılmış silikon } \\
\text { dioksit }\end{array}$ & $\begin{array}{l}\text { Hacimce } \\
\% 59\end{array}$ & $\begin{array}{l}\text { Heraeus, } \\
\text { Kulzer }\end{array}$ & $010501 \mathrm{~A}$ \\
\hline $\begin{array}{l}\text { Ketac } \\
\text { Molar } \\
\text { Easymix }\end{array}$ & $\begin{array}{l}\text { Geleneksel } \\
\text { cam } \\
\text { iyonomer } \\
\text { siman }\end{array}$ & $\begin{array}{l}\text { Toz: Al-Ca-La flor cam, } \\
\% 5 \text { kopolimer asit } \\
\text { (akrilik ve maleik asit) } \\
\text { Likit: Polialkenoik asit, } \\
\text { tartarik asit, su }\end{array}$ & - & $\begin{array}{l}3 \mathrm{M} \\
\mathrm{ESPE}\end{array}$ & 620200 \\
\hline X-tra fil & $\begin{array}{l}\text { Posterior } \\
\text { (bulk fil) } \\
\text { kompozit }\end{array}$ & $\begin{array}{l}\text { Farklı dimetakrilat } \\
\text { karısımları, UDMA, Bis- } \\
\text { GMA, silikat } \\
\text { doldurucular, } \\
\text { inisiyatörler, } \\
\text { pigmentler, aminler, } \\
\text { katkı maddeleri }\end{array}$ & $\begin{array}{l}\text { Hacimce } \\
\% 70.1 \\
\text { Ağırıkça } \\
\% 86\end{array}$ & Voco & 1516628 \\
\hline $\begin{array}{l}\text { Filtek } \\
\text { Z550 }\end{array}$ & $\begin{array}{l}\text { Nanohibrit } \\
\text { universal } \\
\text { kompozit }\end{array}$ & $\begin{array}{l}\text { Rezin: BIS-GMA, } \\
\text { UDMA, BIS-EMA, } \\
\text { PEGDMA ve TEGDMA } \\
\text { Doldurucu: Yüzey } \\
\text { modifiye } \\
\text { zirkonyum/silika }\end{array}$ & $\begin{array}{l}\text { Hacimce } \\
\% 67.8 \\
\text { Ağırlıkça \% } \\
81.8\end{array}$ & $\begin{array}{l}3 \mathrm{M} \\
\mathrm{ESPE}\end{array}$ & N751485 \\
\hline
\end{tabular}

oluşturmak için cam ve şeffaf matris bandı arasına yerleştirilerek hazırlandı. Rezin esaslı materyaller her iki yüzden, 20 saniye ışıkla (LED, Elipar S10, 3M-ESPE, ABD) polimerize edildi. Işık yoğunluğu $1200 \mathrm{~mW} / \mathrm{cm}^{2}$ olarak ölçüldü ve her grup öncesinde ışık kaynağının batarya seviyesi ve ışık yoğunluğu kontrol edildi. Işık kaynağı örneklere temas etmeden olabilecek en yakın mesafede konumlandırılarak kullanıldı. Örnekler $37^{\circ} \mathrm{C}$ 'de 28 gün desikatörde bekletildi. Daha sonra hassas terazi (Ohaus Adventurer, AR3130, Çin) ile ağırlık ölçümü yapılarak $m_{1}$ 
değerleri elde edildi. Hacim $\left(V=\pi r^{2} \quad h\right)$ hesaplaması yapmak üzere örneklerin çap ve yükseklikleri dijital kumpas (TorQ Digital Caliper, Çin) ile ölçüldü ve kaydedildi. Örneklerin başlangıç mikrosertlik ölçümleri, mikrosertlik cihazı (HMV-2, Microhardness Tester, Shimadzu, Japonya) ile 15 saniye süreyle 50 mNewton kuvvet uygulanarak yapıldı ve $\mathrm{VH}_{1}$ değerleri elde edildi.

Örnekler daha sonra 28 gün boyunca distile suda bekletildi. Olası pH değişimini önlemek için distile su haftalık olarak yenilendi. 28 gün sonunda örnekler distile sudan çıkarıldı ve kurulandı. İkinci kez ağırlık ölçümü $\left(m_{2}\right)$ ve mikrosertlik ölçümü $\left(\mathrm{VH}_{2}\right)$ yapıldı. Daha sonra örnekler $37^{\circ} \mathrm{C}$ 'de 90 gün desikatörde bekletildi. $\mathrm{Bu}$ bekleme süresi sonrasında üçüncü kez ağırlık $\left(\mathrm{m}_{3}\right)$ ve mikrosertlik $\left(\mathrm{VH}_{3}\right)$ ölçümleri yapıldı.

Su emilimi (WS) ve çözünürlük (SL), aşağıda belirtilmiş olan formüller ${ }^{11,12}$ kullanılarak ISO 4049 standartlarına göre hesaplandı.

$\mathrm{WS}=\left(\mathrm{m}_{2}-\mathrm{m}_{3}\right) / \mathrm{V}$

$S L=\left(m_{1}-m_{3}\right) / V$

Verilerin istatistiksel analizi IBM SPSS (SPSS Inc, Chicago Illinois, $A B D$ ) programı ile \% 95 güven aralığında tek yönlü varyans analizi (ANOVA) ve Bonferroni testi ile gerçekleştirildi.

\section{BULGULAR}

Verilerin normal dağılım gösterdiği Shapiro-Wilk testi ile belirlendi $(p>0.05)$. ANOVA sonuçlarına göre WS, SL, $\mathrm{VH}_{1}, \mathrm{VH}_{2}$ ve $\mathrm{VH}_{3}$ değerlerinin gruplar arasında farklılık gösterdiği belirlendi $(p<0.05)$.

Örneklere ait WS, $\mathrm{SL}, \mathrm{VH}_{1}, \mathrm{VH}_{2}$ ve $\mathrm{VH}_{3}$ değerleri Tablo 2'de gösterilmiştir. Çalışmada test edilen tüm kompozit materyaller ISO 4049 kriterlerine uygun olarak $40 \mu \mathrm{g} / \mathrm{mm}^{3}$ 'den daha az su emilimi gösterdi. Bu kriterlere uymayan ve en yüksek WS değeri ise sadece cam iyonomer siman olan Ketac Molar Easymix'de $\left(78.44 \pm 5.14 \mu \mathrm{g} / \mathrm{mm}^{3}\right)$ saptandı $(p<0.05)$. Kompozit materyaller arasında en az su emiliminin, $X$-tra fil grubunda $(9.61 \pm 4.9)$ meydana geldiği saptandı. Test edilen materyallerin tümü ISO 4049 kriterlerine uygun olarak $7.5 \mu \mathrm{g} / \mathrm{mm}^{3}$ 'den daha az çözünürlük değerleri gösterdi. G-aenial posterior, Charisma Smart, X-tra fil ve Filtek Z550 gruplarında negatif çözünürlük değerleri saptanması, kurutma süresince suyun tamamen uzaklaştıılamadığını göstermektedir.
Tablo 2.

Su emilimi, çözünürlük ve mikrosertlik için ortalama \pm standart sapma değerleri

\begin{tabular}{|c|c|c|c|c|c|}
\hline Materyal & $\begin{array}{l}\text { WS } \\
(\mu \mathrm{g} / \mathrm{mm} 3)\end{array}$ & $\begin{array}{l}\mathrm{SL} \\
(\mu \mathrm{g} / \mathrm{mm} 3)\end{array}$ & VH1 & VH2 & VH2 \\
\hline $\begin{array}{l}\text { Ceram-X } \\
\text { One } \\
\text { Universal }\end{array}$ & $17.49 \pm 6.61^{\mathrm{a}}$ & $1.47 \pm 3.11^{\mathrm{a}, \mathrm{b}}$ & $58.63 \pm 4.97^{\mathrm{a}, \mathrm{c}}$ & $48.48 \pm 6.15^{\mathrm{a}}$ & $52.42 \pm 7.39^{a}$ \\
\hline $\begin{array}{l}\text { G-aenial } \\
\text { posterior }\end{array}$ & $13.53 \pm 5.17^{\mathrm{a}, \mathrm{b}}$ & $1.22 \pm 4.07^{\text {ab, }, c}$ & $40.33 \pm 5.46^{a}$ & $29.72 \pm 1.73^{b}$ & $29.94 \pm 7.06^{b}$ \\
\hline $\begin{array}{l}\text { Charisma } \\
\text { Smart }\end{array}$ & $15.03 \pm 3.04^{\mathrm{a}, \mathrm{b}}$ & $0.07 \pm 4.36^{\mathrm{a}, \mathrm{b}, \mathrm{c}}$ & $54.85 \pm 5.51^{\mathrm{a}}$ & $44.66 \pm 5.58^{a, b}$ & $37.75 \pm 8.48^{\mathrm{b}}$ \\
\hline $\begin{array}{l}\text { Ketac } \\
\text { Molar } \\
\text { Easymix }\end{array}$ & $78.44 \pm 5.14^{c}$ & $4.90 \pm 5.81^{\mathrm{a}}$ & $94.60 \pm 18.21^{b}$ & $82.50 \pm 21.38^{c}$ & $50.33 \pm 5.22^{\mathrm{a}}$ \\
\hline X-tra fil & $9.61 \pm 4.9^{b}$ & $-4.00 \pm 5.56^{b, c}$ & $76.29 \pm 12.41^{b, c}$ & $62.5 \pm 7.34^{\mathrm{a}, \mathrm{d}}$ & $47.94 \pm 9.63^{\mathrm{a}}$ \\
\hline Filtek & $15.31 \pm 6.66^{\mathrm{a}, \mathrm{b}}$ & $-4.79 \pm 3.32^{c}$ & $78.55 \pm 8.08^{b}$ & $67.65 \pm 4.62^{\mathrm{c}, \mathrm{d}}$ & $44.49 \pm 3.12^{\mathrm{a}}$ \\
\hline
\end{tabular}

Aynı sütündaki aynı üst simgeye sahip değerler istatistiksel olarak farksızdır (p>0.05)

WS: su emilimi, SL: çözünürlük, VH1: başlangıç mikrosertlik değeri, VH2: suda bekletme sonrası mikrosertlik değeri, VH3: desikatörde su uzaklaştırıldıktan sonraki mikrosertlik değeri

Su emilimi, çözünürlük ve üç farklı zaman aralığındaki mikrosertlik değerleri arasındaki korelasyon incelendiğinde materyallere göre farklılık olduğu belirlendi. Ceram- $X$, Charisma Smart ve Filtek Z550 gruplarında WS, SL, VH $\mathrm{VH}_{2}$ ve $\mathrm{VH}_{3}$ arasında korelasyon olmadığı belirlendi. Gaenial Posterior grubunda sadece $\mathrm{VH}_{2}$ ve $\mathrm{VH}_{3}$ arasında pozitif anlamlı bir korelasyon olduğu belirlendi $(r=0.816$, $\mathrm{p}<0.05)$. Ketac Molar Easymix grubunda; $\mathrm{SL}$ ve $\mathrm{VH}_{1}$ arasında negatif anlamlı bir korelasyon olduğu belirlendi $(r=-0.962, p<0.05)$. X-tra fil grubunda WS ve SL arasında pozitif anlamlı bir korelasyon olduğu belirlendi $(r=0.679$, $\mathrm{p}<0.05)$.

Başlangıç mikrosertlik değerleri incelendiğinde; en yüksek mikrosertlik değerleri sırasıyla Ketac Molar $(94.60 \pm 18.21)$, Filtek Z-550 $(78.55 \pm 8.08)$ ve X-tra fil $(76.29 \pm 12.41)$ gruplarında gözlendi ve bu gruplar arasında istatistiksel olarak anlamlı farklılık yoktu. En düşük başlangıç mikrosertlik değerleri ise sırasıyla G-aenial posterior $(40.33 \pm 5.46)$, Charisma Smart $(54.85 \pm 5.51)$ ve Ceram-X One Universal $(58.63 \pm 4.97)$ gruplarında saptandı ve bu gruplar arasında da istatistiksel olarak anlamlı farklılık yoktu. Ayrıca X-tra fil ve Ceram-X One Universal başlangıç mikrosertlik değerleri arasında anlamlı farklılık olmadığı saptandı (Tablo 2). Her bir materyal için üç farklı zaman aralığındaki mikrosertlik değerleri incelendiğinde; mikrosertlik değerlerinde azalma yönünde bir gidişat olduğu görüldü. Karşılaştırmalar Tablo 3'de gösterilmiştir. 
Tablo 3.

Üç farklı zaman aralığında, mikrosertlik için ortalama \pm standart sapma değerleri.

\begin{tabular}{llll|} 
Materyal & VH1 & VH2 & VH3 \\
\hline $\begin{array}{l}\text { Ceram-X } \\
\text { One } \\
\text { Universal }\end{array}$ & $58.63 \pm 4.97^{\mathrm{a}}$ & $48.48 \pm 6.15^{\mathrm{a}}$ & $52.42 \pm 7.39^{\mathrm{a}}$ \\
\hline $\begin{array}{l}\text { G-aenial } \\
\text { posterior }\end{array}$ & $40.33 \pm 5.46^{\mathrm{a}}$ & $29.72 \pm 1.73^{\mathrm{b}}$ & $29.94 \pm 7.06^{\mathrm{a}, \mathrm{b}}$ \\
\hline $\begin{array}{l}\text { Charisma } \\
\text { Smart }\end{array}$ & $54.85 \pm 5.51^{\mathrm{a}}$ & $44.66 \pm 5.58^{\mathrm{a}, \mathrm{b}}$ & $37.75 \pm 8.48^{\mathrm{b}}$ \\
\hline Ketac Molar & $94.60 \pm 18.21^{\mathrm{a}}$ & $82.50 \pm 21.38^{\mathrm{a}, \mathrm{b}}$ & $50.33 \pm 5.22^{\mathrm{b}}$ \\
\hline X-tra fil & $76.29 \pm 12.41^{\mathrm{a}}$ & $62.5 \pm 7.34^{\mathrm{a}}$ & $47.94 \pm 9.63^{\mathrm{b}}$ \\
\hline Filtek Z550 & $78.55 \pm 8.08^{\mathrm{a}}$ & $67.65 \pm 4.62^{\mathrm{a}}$ & $44.49 \pm 3.12^{\mathrm{b}}$ \\
\hline
\end{tabular}

Aynı satırdaki aynı üst simgeye sahip değerler istatistiksel olarak farksızdır ( $p>0.05)$ başlangıç mikrosertlik değeri, VH2: suda bekletme sonrası mikrosertlik değeri, VH3: desikatörde su uzaklaştırıldıktan sonraki mikrosertlik değeri

\section{TARTIŞMA}

$\mathrm{Bu}$ in vitro çalışmada posterior bölgede kullanılmak üzere mekanik özellikleri geliştirilmiş olan beş farklı kompozit rezin test edildi. Ayrıca sertleşme mekanizmasında suyun oldukça önemli olduğu bilinen bir geleneksel cam iyonomer siman (Ketac Molar Easymix) da negatif kontrol grubunu temsil etmek üzere çalışmaya dahil edildi. Çalışma bulguları cam iyonomer simanın (Ketac Molar Easymix) daha önceki çalışmalarla uyumlu olarak en yüksek su emilimi ve çözünürlük değerlerini sergilediğini göstermektedir. ${ }^{13-15} \mathrm{Bu}$ durumun, materyalin erken dönemde neme hassasiyeti ile doğrudan ilişkili olduğunu düşünmekteyiz. Çalışmamızda cam iyonomer siman yüzeye herhangi bir vernik uygulaması yapılmaksızın test edilmiştir. Vernik uygulaması sonrası bu materyalin çözünürlük ve su emilimi değişkenlik gösterebilir, bunun ileri çalışmalarla incelenmesi gereklidir. Ketac Molar Easymix'in ISO 4049 kriterlerinin dışında $\left(78.44 \pm 5.14 \quad \mu \mathrm{g} / \mathrm{mm}^{3}\right) \quad$ su emilimi göstermesi dikkat çekicidir. Dolayısıyla geleneksel bir cam iyonomer siman olan Ketac Molar Easymix'in posterior bölgede restorasyon materyali olarak tercih edilmeyip kompozit restorasyonların altında kaide maddesi olarak kullanımı, şimdilik uzun dönem klinik başarı açısından daha temkinli bir yaklaşım olacaktır. Öte yandan piyasada güçlendirilmiş cam iyonomerlerin yanı sıra, cam iyonomer siman ve kompozit rezinlerin avantajlarını bünyesinde bulunduran rezin modifiye cam iyonomerler ve kompomerler de mevcuttur. Dolayısıyla ileri çalışmalarda bu materyallerin de incelenmesi, klinisyenlere intiyaçları doğrultusunda uygun materyal seçimi açısından fayda sağlayabilir.
Çalışmada test edilen rezin kompozitlerin her biri farklı doldurucu oranlarına sahip olup, farklı monomerler içermektedir. Kompozit rezinlerin doldurucu tipi, oranları ve organik matris bileşenlerindeki farklılıklar doğal olarak sonuçları farklı etkilemiştir. Kompozit rezinlerdeki su emilimi bir tür difüzyon süreci olarak yorumlanabilir. Su emilimi ve çözünürlük polimerlerin yapı ve fonksiyonunda hasar oluşturarak materyalin fiziksel ve mekanik özelliklerinde değişikliklere neden olabilir. ${ }^{16}$ Organik matristeki monomerlerin hidrofobik yapısı rezin materyallerin su emiliminde etkili unsurlardandır. ${ }^{17}$ Hidrofilik bir monomer olan BisGMA'nın su absorbsiyonu ve suda çözünme miktarının yüksek olduğu bildirilmiştir. ${ }^{18,19}$ Çalışmamızda Bis-GMA içeren ve içermeyen kompozit rezinlerin benzer su emilimi ve çözünürlük sergilediği saptanmıştır. Bu durumun materyallerin içeriğinde Bis-GMA'nın tek başına bulunmamasından, farklı diğer monomerlerle kombinasyon şeklinde yer almış olmasından kaynaklanmış olabileceğini düşünmekteyiz.

Rezin esaslı materyallerde su emilimi ve çözünürlüğün doldurucu oranıyla ilişkili olduğu pek çok çalışmada bildirilmiştir. Çalışmada test edilen materyaller arasında en yüksek doldurucu oranına sahip iki materyal sırasıyla X-tra fil (hacimce \% 70.1 ve ağırlıkça $\%$ 83.5) ve Filtek $Z 550$ (hacimce \% 68 ve ağırlıkça \% 82) dir. Bu iki materyallerdeki yüksek doldurucu oranlarıyla ilişkili olarak materyaller arasında en düşük su emilimi X-tra fil $(9.61 \pm 4.9)$, en düşük çözünürlük ise Filtek Z550 (-4.79 3 3.32) grubunda saptanmıştır. Bu bulgular rezin esaslı materyallerde su emilimi ve çözünürlüğün yüksek doldurucu oranına sahip materyallerde daha düşük olduğunu bildiren önceki çalışmaların sonuçlarıyla uyumludur. ${ }^{11-13,20}$ Öte yandan, G-aenial posterior, Charisma Smart, X-tra fil ve Filtek Z550 gruplarında gözlenen negatif çözünürlük değerleri birer yanılsama olarak nitelendirilebilir. Bu durum materyallerin hidrofobitesinin materyalin içinden ve dışından solvent geçişini zorlaştırması ve su moleküllerinin hapsolması ile ilişkilidir. ${ }^{11}$ Ceram-X'deki organik-inorganik matrisin hidrofobik bir polimer ağı sağlayabileceği ve bu yapının materyalde daha düşük su emilimine neden olduğu bildirilmiştir. ${ }^{21}$ Ancak çalışmamızda, Ceram-X One Universal diğer nanohibrit kompozitlerden daha üstün bir performans sergilememiştir.

Rezin kompozitlerin doldurucu oranı ve sertlikleri arasında pozitif bir korelasyon olduğu bildirilmiştir. ${ }^{22,23}$ Çalışmamızda da önceki çalışma bulgularılyla uyumlu olarak kompozit rezinler arasında en yüksek mikrosertlik değerleri, en yüksek doldurucu oranına sahip X-tra fil (hacimce \% 70.1 ve ağırlıkça \% 86) ve Filtek Z550 (hacimce \% 67.8 ve ağırlıkça \% 81.8) gruplarında saptanmıştır.. Ayrıca literatürle uyumlu olarak nanohibrit kompozitlerin mikrohibrit kompozit materyallere göre mikrosertlik değerlerinin daha 
yüksek olduğu saptanmıştı. ${ }^{22}$ Suda bekletme ve dehidratasyon işlemlerini takiben materyallerin mikrosertlik değerlerinde azalma yönünde bir eğilim olduğu dikkat çekmektedir. Üç farklı zaman aralığındaki mikrosertlik değerleri $\left(\mathrm{VH}_{1}, \mathrm{VH}_{2}\right.$ ve $\left.\mathrm{VH}_{3}\right)$ arasında farkllık bulunmayan tek materyal Ceram-X One Universal'dir. Öte yandan Ketac Molar Easymix'in birinci zaman aralığında en yüksek mikrosertlik değerine sahip olmasına karşın, suda bekletme ve dehidratasyon işlemlerini takiben mikrosertlik değerindeki düşüş dikkat çekicidir.

$\mathrm{Bu}$ in vitro çalışmanın sınırları dahilinde su emilimi, çözünürlük ve üç farklı zaman aralığındaki mikrosertlik değerleri arasındaki korelasyonun materyallere göre farklılık gösterdiği belirlenmiştir. Bu durumun her bir materyalin içeriğindeki komponentler ve bunların etkileşimindeki farklıııkan kaynaklanmış olabileceğini düşünmekteyiz. Öte yandan çalışmamızda materyaller herhangi bir yaşlandırma prosedürü uygulanmadan test edilmiştir. Ağız içi koşullarda materyalin mekanik özelliklerinin uzun dönemde değişiklik gösterebileceği bilinmektedir. Bu nedenle materyallere yaşlandırma prosedürünün uygulandığı ileri çalışmalar, uzundönem performans açısından bilgi sağlayacağı için faydalı olabilir. Bu konu ile ilgili bir çalışmada, yaşlandırma prosedüründe farklı ortamların (su, tükürük) farklılık oluşturabileceği bildirilmiştir. ${ }^{12}$ Dolayısıyla ileri çalışma tasarımında bu faktörün de göz önünde bulundurulması fayda sağlayabilir. Bu çalışmadaki en önemli sınırlamalardan biri negatif kontrol grubu olarak tasarlanan Ketac Molar Easymix'in vernik uygulanmaksızın test edilmesidir. Bu durumun çalışma sonuçlarını etkileyebileceği göz önünde bulundurularak, ileri çalışmalarda vernik uygulamasının cam iyonomer simanın WS, SL ve mikrosertlik değerlerine etkisinin incelenmesi faydalı olacaktır.

Sonuç olarak çalışma bulguları göz önünde bulundurulduğunda, yüksek doldurucu oranına sahip rezin materyallerin mekanik özellikler açısından iyi performans sağladıkları görülmektedir. Çözünürlük, su emilimi ve mikrosertlik gibi temel mekanik özellikler klinisyenlerin materyal seçiminde etkili olsa da, materyallerin diğer fiziksel, kimyasal ve biyolojik özelliklerinin de dikkate alınması gerektiği unutulmamalıdır.

\section{Teşekkür}

Verilerin istatistiksel analizdeki katkılarından dolayı Arş. Gör. Hatice ULUER'e içtenlikle teşekkür ederiz. 


\section{KAYNAKLAR}

1. Simecek JW, Diefenderfer KE, Cohen ME. An evaluation of replacement rates for posterior resinbased composite and amalgam restorations in US. Navy and marine corps recruits. J Am Dent Assoc 2009; 140(2): 200-9.

2. Yiu CK, King NM, Pashley DH, Suh BI, Carvalho RM, Carrilho MR et al. Effect of resin hydrophilicity and water storage on resin strength. Biomaterials 2004; 25(26): 5789-96.

3. Ito S, Hashimoto M, Wadgaonkar B, Svizero N, Carvalho RM, Yiu C et al. Effects of resin hydrophilicity on water sorption and changes in modulus of elasticity. Biomaterials 2005; 26(33): 6449-59.

4. Göhring TN, Besek MJ, Schmidlin PR. Attritional wear and abrasive surface alterations of composite resin materials in vitro. J Dent 2002; 30: 119-27.

5. Ferracane JL. Hygroscopic and hydrolytic effects in dental polymer networks. Dent Mater 2006; 22(3): 211-22.

6. Alrahlah A, Silikas N, Watts DC. Hygroscopic expansion kinetics of dental resin-composites. Dent Mater 2014; 30(2): 143-8.

7. Rüttermann $S$, Krüger $S$, Raab WHM, Janda R. Polymerization shrinkage and hygroscopic expansion of contemporary posterior resin-based filling materials-a comparative study. J Dent 2007; 35(10): 806-13.

8. Guggenberger R, Weinmann W. Exploring beyond methacrylates. Am J Dent 2000; 30: 10-5.

9. Mitra SB, Dong W, Holmes BN. An application of nanotechnology in advanced dental materials. JADA 2003; 134: 1382-90.

10.Jan SM, Mir RA, Behal R, Shafi M, Kirmani M, Bhat MA. Role of Nanotechnology in Dentistry. Sch J App Med Sci 2014; 2(2D): 785-9.

11.Boaro LC, Gonçalves F, Guimarães TC, Ferracane JL, Pfeifer CS, Braga RR. Sorption, solubility, shrinkage and mechanical properties of "lowshrinkage" commercial resin composites. Dent Mater 2013; 29(4): 398-404.

12.Alshali RZ, Salim NA, Satterthwaite JD, Silikas N. Long-term sorption and solubility of bulk-fill and conventional resin-composites in water and artificial saliva. J Dent 2015; 43(12): 1511-8.

13. Sevilmiş HH, Bulucu B. Adeziv Materyallerin Su Emilimi Özellikleri. Hacettepe Dişhek Fak Derg 2007; 31(2): 16-21.

14. Yıkılgan I, Gürel MA, Bala O, Ömürlü H. Farklı Estetik Restoratif Materyallerin Su Emilimi ve Suda Çözünürlüklerinin Karşılaştırılması. Gazi Üniversitesi Diş Hek Fak Derg 2010; 27(2): 93-8.

15. Ayna BE, Çelenk S, Bolgül BS, Atakul F, Uysal E. Water Sorption and Water Solubility of Various Restorative Materials. Türrkiye Klinikleri J Dent Sci 2006; 12: 43-6.
16. Malacarne J, Carvalho RM, de Goes MF, Svizero $\mathrm{N}$, Pashley $\mathrm{DH}$, Tay FR et al. Water sorption/solubility of dental adhesive resins. Dent Mater 2006; 22(10): 973-80.

17. Ortengren $U$, Andersson F, Elgh U, Terselius B, Karlsson $\mathrm{S}$. Influence of $\mathrm{pH}$ and storage time on the sorption and solubility behaviour of three composite resin materials. J Dent 2001; 29: 3541.

18. Sideridou I, Terski V, Papanastasiou G. Study of water sorption, solubility and modulus of elasticity of light-cured dimethacrylatebased dental resins. Biomaterials 2003; 24: 655-65.

19.Atai M, Nekoomanesh M, Hashemi SA. Physical and mechanical properties of an experimental dental composite based on a new monomer. Dent Mater 2004; 20: 663-8.

20.Şahin D, Kapdan A, Ünal M, Hürmüzlü F. Farklı Yapıdaki Kompozit Rezin Materyallerinin Su Emilimi ve Suda Çözünürlük Değerlerinin Karşılaştııııması. Cumhuriyet Üniversitesi Dişhek Fak Derg 2009; 12(1): 22-8.

21. Fonseca AS, Gerhardt KM, Pereira GD, Sinhoreti MA, Schneider LF. Do new matrix formulations improve resin composite resistance to degradation processes? Braz Oral Res 2013; 27(5): 410-6.

22. Tekçe N, Pala K, Tuncer S, Demirci M. The effect of surface sealant application and accelerated aging on posterior restorative surfaces: An SEM and AFM study. Dent Mater J 2017; 36(2): 182-9.

23. Chung $\mathrm{KH}$. The relationship between composition and properties of posterior resin composites. J Dent Res 1990; 69: 852-6.

Yazışma Adresi:

Dr. Çiğdem ATALAYIN

Ege Üniversitesi

Diş Hekimliği Fakültesi

Restoratif Diş Tedavisi AD

35100, Bornova, İzmir

Tel : +90 2323112887

Faks : +90 2323880325

E-mail: dtcatalayin@gmail.com 